\title{
Avaliação de técnicas de processamento de imagem na identificação de impactos ambientais em linha de transmissão de energia elétrica
}

\author{
Evaluation of image processing techniques in environmental impact identification in \\ powerline \\ Claudionor Ribeiro Silva1, Samuel Lacerda de Andrade e Admilson Penha Pacheco ${ }^{3}$ \\ ${ }^{1,2}$ Universidade Federal de Uberlândia, SP, Brasil \\ crs@ig.ufu.br; samuelgeoudi@gmail.com \\ ${ }^{3}$ Universidade Federal do Pernambuco, PE, Brasil \\ pacheco3p@gmail.com
}

\begin{abstract}
Resumo
Os empreendimentos do setor energético são compostos basicamente por cabos e estruturas metálicas. Embora traga benefícios, a instalação e operação desses empreendimentos apresentam impactos ambientais relevantes ao longo do seu trajeto. Este trabalho tem como objetivo avaliar técnicas de processamento de imagem para identificar impactos ambientais em Linha de Transmissão (LT) de Energia Elétrica (Trecho: Ibicoara/BA x Brumado/BA). Foram realizados testes em ortofotos com a classificação MaxVer e com processo de Segmentação orientado ao objeto, com experimentos integrando dados Laser Scanner. Os resultados foram analisados com base nos erros de comissão (acurácia do usuário), omissão (acurácia do produtor) e índice kappa. Segundo o índice Kappa calculado, todos os testes realizados apresentaram classificações enquadradas como excelentes. A utilização de dados laser scanner integrados com ortofotos demonstrou um avanço no refinamento dos resultados, apresentando maior acurácia tanto na classificação quanto na segmentação. Os principais indícios de impactos ambiental localizados na área de estudo estão relacionados com a exposição do solo para aberturas de acessos e implantação das infraestruturas da LT e para o uso/ocupação na agropecuária. A área de solo exposto medida nos experimentos é de $16 \%$, demonstrando a necessidade de ações de prevenção e conservação em projetos de LT.
\end{abstract}

Palavras-chave: LiDAR. Ortofoto. Segmentação

\begin{abstract}
The projects in the energy sector are basically composed of cables and metal structures. While providing benefits, installation and operation of these projects have significant environmental impacts along its path. The aim of this study was to evaluate image processing techniques to identify environmental impacts in energy powerline (path: Ibicoara-Brumado in Bahia / Brazil). Tests were performed on orthophotos with MaxVer classification and segmentation process object-oriented, with experiments integrating $L i D A R$. The results were analyzed on the basis of commission errors (user accuracy), omission errors (producer accuracy) and kappa index. According to Kappa index calculated, all tests showed ratings classified as excellent. The use of integrated LiDAR with orthophotos demonstrated an improvement in refining the results, with higher accuracy in classification and segmentation. The main evidence of environmental impacts is areas with exposed soil related to access roads, implementation of the infrastructure and useloccupation with agriculture. The area related to exposed soil was $16 \%$ demonstrating the need for prevention and conservation actions in LT projects.
\end{abstract}

Keywords: LiDAR. Ortophoto. Segmentation 


\section{Introdução}

O crescimento econômico de um país passa pela ampliação e modernização do seu sistema energético. O Brasil possui potencial energético privilegiado, sendo que os empreendimentos exploradores desses potenciais são muito diversificados. As Linhas de Transmissão Energia (LT), no território brasileiro, apresentam grandes extensões devido à longa distância entre as unidades produtoras de energia e os centros urbanos consumidores (ANEEL, 2014; SILVA et al., 2014).

Essas obras de engenharia (LT) podem apresentar impactos ambientais por um perímetro geralmente longo, que delimita toda a sua faixa de implantação/ exploração. Para analisar essas grandes áreas, os setores de planejamento, bem como os projetos de expansão do sistema elétrico, demandam informações espaciais precisas, elaboradas em formato digital ou mesmo em mapas impressos. A aplicação de tecnologia informatizada e de geotecnologia pode significar um melhoramento nas análises espaciais do setor, tornando os processos de tomada de decisão mais rápidos, eficientes e menos onerosos (RIMA, 2014; SILVA et al., 2014).

Tratando-se de empreendimentos elétricos, em específico das linhas de transmissão de energia, o Brasil possui uma rede elétrica extensa, devido a sua territorialidade, necessitando de uma solução prática e eficaz no que diz respeito a diagnósticos e monitoramento de faixas de servidão. As linhas de transmissão se estendem por quilômetros, dificultando o acesso em áreas distantes dos centros urbanos e, consequentemente, prejudicando a manutenção / monitoramento das estruturas e os aspectos relacionados aos impactos ambientais, que ocorrem principalmente devido a sua implantação e ao uso controlado da faixa de servidão (ANEEL, 2014; SILVA et al., 2014).

A utilização de produtos refinados nesse processo de modernização e a inserção de novas técnicas, como as fotos áreas e os produtos LiDAR, pode permitir resultados mais acurados no processo de identificação de feições do uso e ocupação do solo. Esses produtos de alta qualidade podem permitir, tecnicamente, ações rápidas e precisas em processo de extração de feições que podem ser úteis na mitigação e reversão de fenômenos como o impacto ambiental (ANDRADE E CENTENO, 2003; BOTELHO E CENTENO, 2005; MAKARAU, et al., 2011).

Esse fator é importante, dado que as imagens e dados altimétricos de baixa resolução espacial não apresentam precisão nos resultados, especialmente em empreendimentos lineares, onde a faixa a ser trabalhada deve ser representada em grandes escalas. Produtos de baixa resolução podem ser utilizados apenas como indicador, necessitando de verificações in locu (SILVA et al., 2014).

Com o surgimento dos novos sistemas de sensores aéreos e orbitais, os classificadores tradicionais, tais como "pixel a pixel" (Máxima Verossimilhança - Maxver) e por regiões (Segmentação), vêm sendo alvo de diversos estudos comparativos (ARCOVERDE et al. 2010), pois o elevado grau de detalhes em imagens de alta resolução espacial apresenta novos desafios. Deve ser considerada a grande confusão espectral causada pela repetição de alvos naturais e sintéticos, pela complexidade e heterogeneidade causadas por tamanho e formas diversas, e composições variadas. Estas características geram a necessidade do surgimento de abordagens que levem em consideração outros atributos, além das características espectrais dos pixels.

Dentre as alternativas de classificação de imagens de alta resolução espacial, a metodologia de análise de imagens baseada em objeto OBIA (object-based image analysis) vem ganhando importância nos últimos anos. Essa técnica surge como um significativo avanço nos processos de classificação automática de imagens, já que possibilita a modelagem do conhecimento humano referente às características específicas dos alvos como brilho, textura, formato, contexto, tamanho, relações de vizinhança, entre outros. A ideia é a classificação de segmentos de imagem (Segmentação) em vez de pixels isolados (BAATZ AND SCHAPE, 2000; HAY AND CASTILLA, 2008; PLATT AND RAPOZA, 2008; PINHO, ET AL., 2012; AND BLASCHKE, 2010).

Este trabalho tem como objetivo avaliar técnicas de processamento de imagem na identificação de impactos ambientais em Linha de Transmissão de Energia Elétrica de 230 KV (Trecho Ibicoara/Brumado/Bahia/Brasil).

\section{Materiais e Métodos}

\section{1 Área de estudo e material usado}

Os quatro fragmentos estudados estão contidos no perímetro da Linha de Transmissão de energia elétrica LT/230 Kw Ibicoara/ Brumado (linha de transmissão pertencente a Companhia Hidroelétrica do Alto do São Francisco- CHESF) correspondente a 46,81Km (Figura 1). A LT em questão corta o perímetro de cinco municípios do estado da Bahia, de Sul para Norte: Brumado, Rio de Contas, Ituaçu, Barra da Estiva e Ibicuara. Está situada entre as coordenadas UTM WGS 84 (Fuso 24): ( $\mathrm{E}=215488.00 \mathrm{~m}, \mathrm{~N}=8426538.00 \mathrm{~m})$, limite inferior e $(\mathrm{E}=243117.00 \mathrm{~m}$ e $\mathrm{N}=8513091.00 \mathrm{~m})$, limite superior.

Foram utilizados os softwares de processamento digital de imagens ENVI 4.8 e ENVI EX, produzidos pela empresa SulSoft. Para a montagem de um banco de dados e pré-análises da região de estudo, foi utilizado o software Arc Gis 10.0 desenvolvido pela empresa Environmental Systems Research Institute (ESRI). A base cartográfica com o posicionamento das torres e as linhas de energia foi cedida pela CHESF.

Devido à grande extensão da LT analisada, foram 


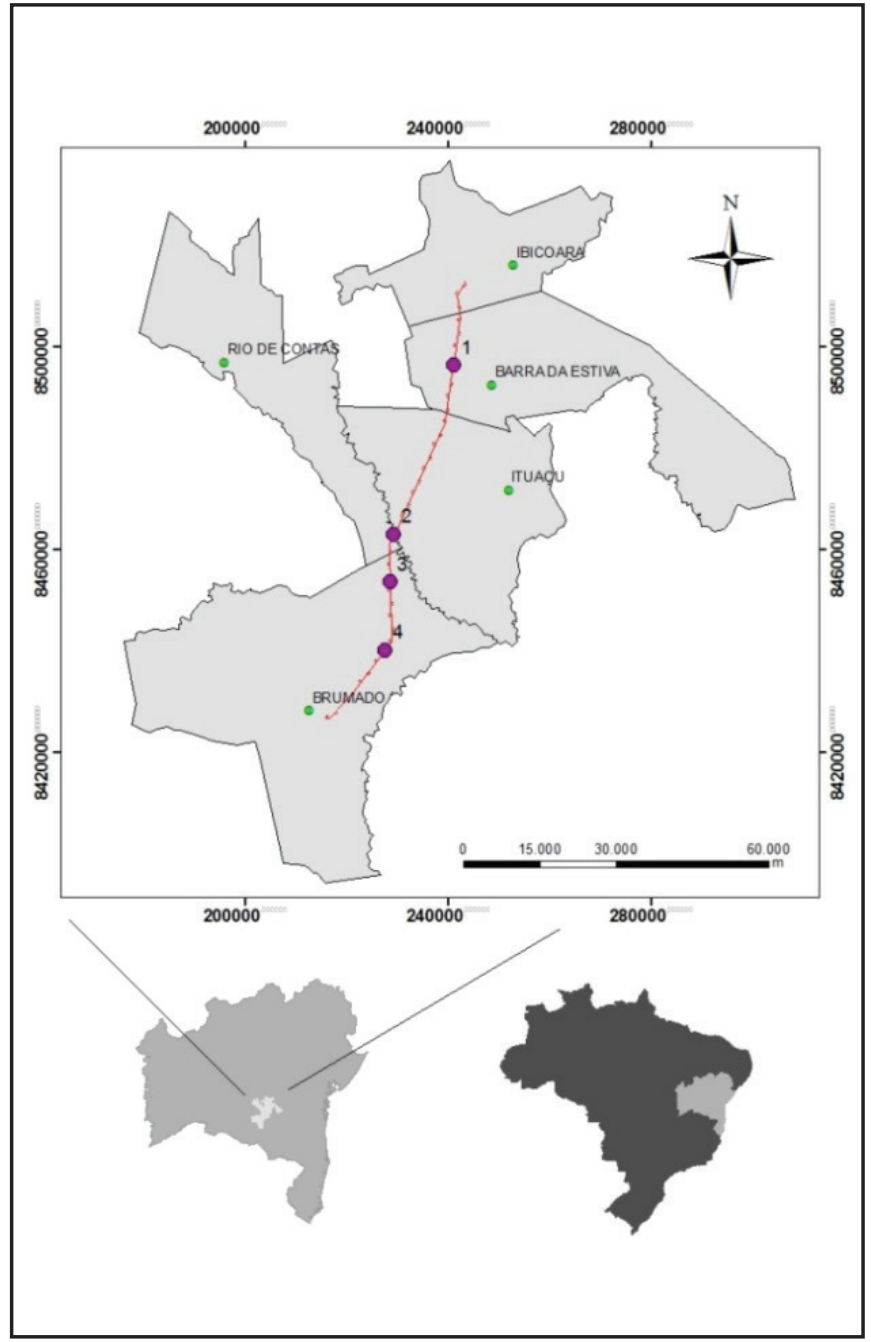

Figura 1 - Localização da área de estudo.

utilizadas fotos aéreas (RGB) de 4 (quatro) recortes da área de interesse (recorte 1, 2, 3 e 4) e dados LiDAR referente a área do recorte 2 . Os recortes $1,2,3$ e 4 possuem tamanhos de $(6064 \times 8628)$ e $(7922 \times 9386)$ (5030X8026) e (8886x94112) pixels, respectivamente; todos com resolução espacial de $0,10 \mathrm{~m}$. As fotografias aéreas multiespectrais foram adquiridas já processadas, sendo somente realizadas correções quanto ao sistema de referência, transformado para o sistema WGS 84, que é compatível com o sistema de origem, o Sirgas2000.

O dado Laser scanner foi coletado com densidade de 15 pontos por $\mathrm{m}^{2}$ e posteriormente reamostrado para uma grade com a mesma resolução espacial das fotos aéreas, usando a interpolação por krigagem.

Os recortes foram escolhidos de forma a representarem locais com incidência de vegetação nativa (grande porte) de área de preservação permanente e reserva legal (mata ciliar), pontos com possível início de processos de erosão/ravinas, e outras feições como solos exposto, cultivo, corpos d’água e pastagem.

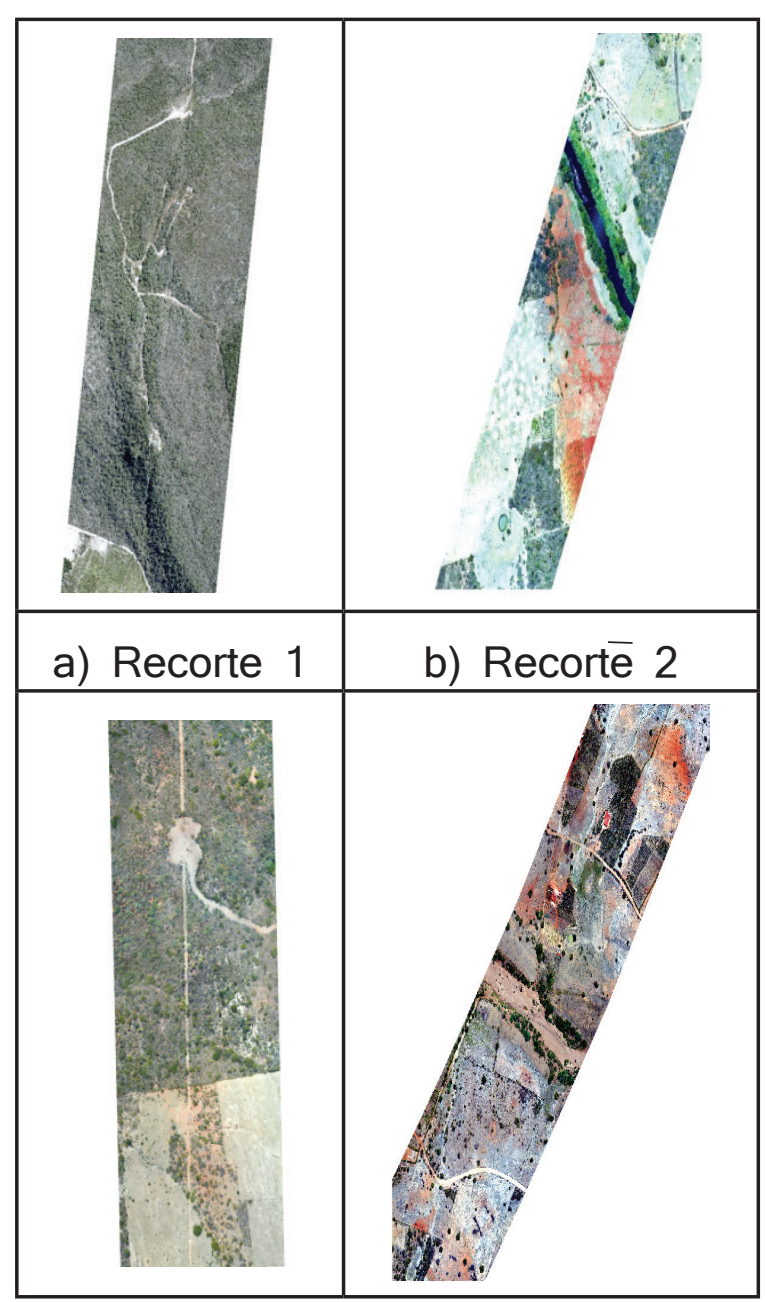

Figura 2 - Recortes da área de estudo

\subsection{Método}

A classificação foi realizada em uma faixa de aproximadamente $150 \mathrm{~m}$, ao redor da LT. A faixa segue o conceito de AID (Área de Influência Direta), como rege a legislação aplicável (Resolução CONAMA 349, artigo $2^{\circ}$ ). Nesse local, geralmente há forte indício de impactos ambientais recorrentes e relevantes das atividades de instalação e manutenção de estruturas. Acredita-se que essa ampliação do universo (faixa mais larga) para aplicação das técnicas de classificação/segmentação permite uma melhor leitura geoespacial sobre os fatores ambientais e antrópicos de ocupação da região, de forma contínua, nos arredores das torres e das linhas/cabos.

Com relação à descrição da metodologia utilizada, para identificar os fatores ambientais de interesse na AID da LT (230 KV) Ibicoara/Brumado, é proposto um fluxograma de segmentação/classificação do conjunto de fotos áreas e dados LiDAR, utilizando o classificador de máxima-verossimilhança e segmentação seguida da classificação com o vizinho mais próximo, implementados no software ENVI 4.8 e ENVI-EX. 


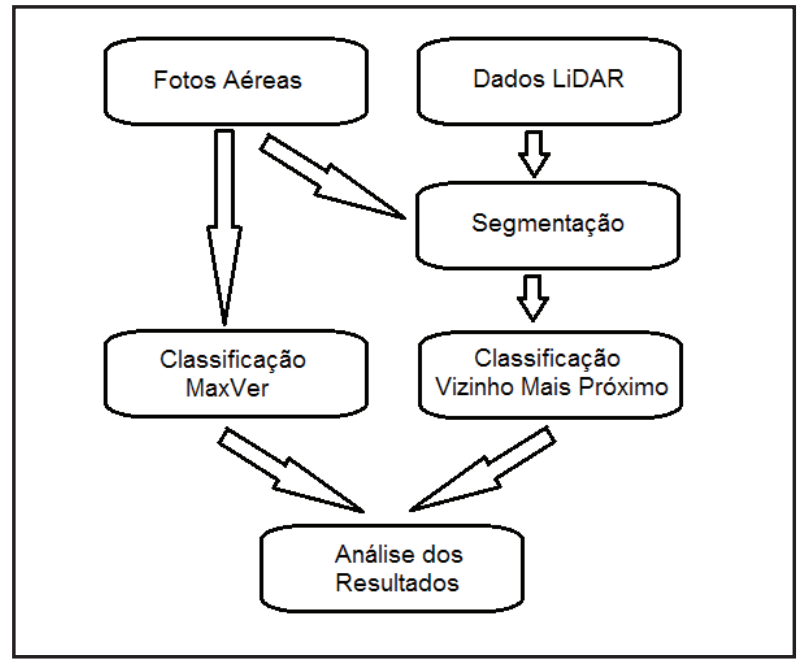

Figura 3 - Fluxograma da metodologia aplicada.

O método é composto de duas etapas: a primeira consiste na classificação das imagens dos quatro recortes da área de estudo, utilizando o classificador da Máximaverossimilhança; e a segunda consiste na classificação e segmentação do conjunto de dados laser scanner integrado com a foto área, ambos da área referente ao recorte 2 (Figura 2b). A segmentação foi realizada com base em parâmetros relacionados com os aspectos: espectral (máximo, mínimo, média e desvio padrão de cada banda), textura (conjunto, média, variância e entropia), espacial (área, comprimento, compactação, convexidade, solidez, forma e alongamento, dentre outros) e customizado (razão de bandas e sistema IHS - Intensidade, Hue e Saturação). Todos os parâmetros descritos acima são apresentados em detalhes no tutorial do software ENVI EX, usado nesse estudo.

Os resultados foram analisados com base nos erros de comissão (acurácia do usuário), omissão (acurácia do produtor) e índice kappa. Os erros de inclusão/comissão referem aos pixels atribuídos a uma determinada classe, oriundos de erros de classificação das outras classes. A acurácia do produtor refere-se aos erros de exclusão/ omissão; isto é, os erros de classificação de outras classes não são atribuídos a uma determinada classe. $\mathrm{O}$ índice kappa é utilizado para a verificação global de concordância entre as amostras de referência das classes usadas e os resultados dos classificadores usados. Os erros de comissão (Ec) e omissão (Eo) e o índice kappa (k) são determinados, respectivamente, pelas equações 1, 2 e 3 .

$$
\begin{array}{r}
E c=\frac{X_{+i}-X_{i i}}{X_{+i}} \\
E o=\frac{X_{i+}-X_{i i}}{X_{i+}} \\
k=\frac{N \cdot \sum X_{i i}-\sum X_{i+} \cdot X_{+i}}{N^{2}-\sum X_{i+} \cdot X_{+i}}
\end{array}
$$

onde, Xii é a concordância observada (diagonal da matriz confusão na posição i); $X_{i+}$ (soma da linha i da matriz confusão) e $X_{+i}$ (soma da coluna i da matriz confusão) são os produtos marginais (concordância esperada); e N é o total de elementos/pixels observados.

A confiabilidade dos resultados obtidos nesse estudo foi analisada de acordo com os intervalos dos valores de kappa propostos por Landis e Koch (1977), conforme Tabela 1.

Tabela 1 - Valores de concordância com base no índice Kappa

\begin{tabular}{c|c}
\hline Índice Kappa (k) & Concordância \\
\hline 0,00 & Pobre \\
\hline 0,00 a 0,20 & Ligeira \\
\hline 0,21 a 0,40 & Considerável \\
\hline 041 a 0,60 & Moderada \\
\hline
\end{tabular}

As amostras das feições de uso e ocupação do solo foram criadas para representar as seguintes classes: "Vegetação Densa”, "Vegetação de Mata Ciliar", "Campo Sujo", "Campo Limpo" (na categoria "Campo Limpo" também inserido os talhões de Agricultura e a Pastagem), "Corpo Hídrico" e "Sombra". Algumas dessas classes não existem em todas as imagens/fotos, portanto não foram consideradas igualmente em todas as cenas.

Com relação às diversas tonalidades encontradas para a mesma classe, como a classe "Solo Exposto", as amostragens foram parceladas em diversas subclasses, tais como "solo 1", "solo 2", "solo n”. As feições "edificações" são difíceis de serem isoladas, como única classe, usando apenas imagem digital, uma vez que a resposta espectral se assemelha à classe "solo exposto". Dessa forma foram consideradas uma única classe.

Destaca-se que foi criada a classe "Fundo" para representar o "Back Ground" das imagens. Portanto, essa classe será excluída da análise. O sombreamento realizado pela vegetação nas imagens, também foi criado a classe "Sombra", essa também será excluída das análises, já que representa apenas pixels de sombreamento na imagem e não uma classe de uso do solo propriamente dita.

\section{Resultados e Discussões}

\subsection{Classificação com fotos aéreas}

A Tabela 2 apresenta as áreas de cada feição correspondente ao uso e ocupação do solo presente nos 4 recortes trabalhados. Em uma análise global, estatisticamente verifica-se a superioridade da área coberta por 
"Campo Sujo", representando 18\% do uso e ocupação do solo, com menos representatividade temos a classe "Água", com 1\%. Destaca-se que foi criada a classe "Fundo", representando o "Back Ground" das imagens, essa classe portanto será excluída da análise; Com o propósito de identificar-se o sombreamento realizado pela vegetação nas imagens, também foi criado a classe "Sombra", essa também será excluída das análises, já que representa apenas pixels de sombreamento na imagem e não uma classe de uso do solo propriamente dita.

Tabela 2 - Áreas das classes analisadas em todos os recortes

\begin{tabular}{|c|c|c|c|c|c|c|}
\hline Classe & $\begin{array}{c}\text { Recorte } \\
1 \\
\end{array}$ & $\begin{array}{c}\text { Recorte } \\
2 \\
\end{array}$ & $\begin{array}{c}\text { Recorte } \\
3 \\
\end{array}$ & $\begin{array}{c}\text { Recorte } \\
4 \\
\end{array}$ & $\begin{array}{c}\text { Total } \\
\text { (ha) }\end{array}$ & $\%$ \\
\hline $\begin{array}{l}\text { Mata } \\
\text { Ciliar }\end{array}$ & 0 & 2,5525 & 0 & 1,4715 & 4,0241 & 2 \\
\hline $\begin{array}{l}\text { Vegetação } \\
\text { Densa }\end{array}$ & 7,0772 & 0 & 1,1747 & 0 & 8,2520 & 4 \\
\hline $\begin{array}{l}\text { Campo } \\
\text { Limpo }\end{array}$ & 5,0819 & 6,9611 & 1,1874 & 20,1996 & 33,4302 & 17 \\
\hline $\begin{array}{l}\text { Campo } \\
\text { Sujo }\end{array}$ & 11,8312 & 12,7417 & 11,7538 & 3,5210 & 36,3268 & 18 \\
\hline $\begin{array}{c}\text { Solo } \\
\text { Exposto }\end{array}$ & 0,3011 & 7,9790 & 16,0849 & 7,3817 & 31,7468 & 16 \\
\hline Sombra & 0 & 0,1193 & 1,1874 & 1,4142 & 2,7210 & 1 \\
\hline Fundo & 25,9959 & 42,9661 & 16,0849 & 11,7538 & 80,7160 & 41 \\
\hline Água & 2,0326 & 1,0358 & 0 & 0 & 1,0358 & 1 \\
\hline
\end{tabular}

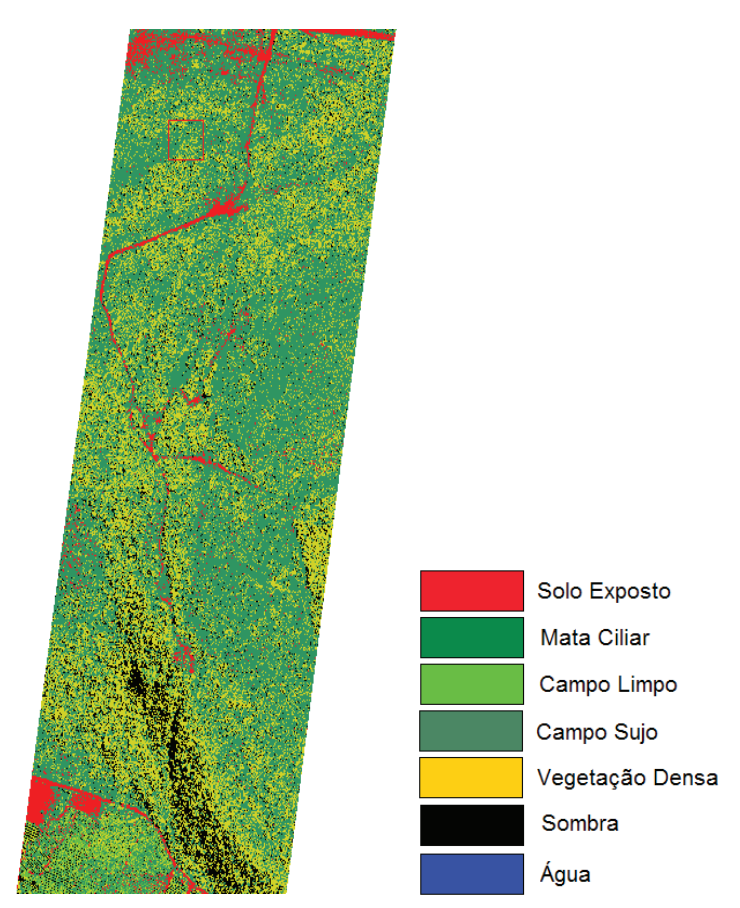

Figura 4 - Imagem classificada referente ao Recorte 1 (legenda de classes válida para todas as imagems classificadas).
Em uma análise visual e com base nos dados estatísticos de classificação do Recorte 1 (Figura 4), a classe dominante é "Campo Sujo", contabilizando 11,831 23 ha, e com menor expressão, a classe "Solo Exposto", contabilizando 0,301118 ha. A classificação por MaxVer se mostrou eficiente na identificação da classe de solos, representando feições como estradas e áreas com solos expostos.

Com relação aos processos de ravinamento, ligados à classe "Solo Exposto", nota-se regiões potenciais ao norte da imagem (Figura 4), áreas que devem ser investigadas por técnicos responsáveis; também há, próximo aos locais de instalação das torres, áreas que possuem o potencial de evolução desse fenômeno, merecendo medidas de contensão.

$\mathrm{O}$ índice Kappa para o primeiro recorte foi 0,8422, colocando a classificação na classe "Excelente", com padrões mínimos de aceitação, segundo a Tabela 2. As feições "Vegetação Densa" e "Campo Sujo' apresentaram maior erro referente a Comissão (Tabela 3), indicando uma confusão entre as classes. Esse erro se dá devido à similaridade da resposta espectral dos alvos na imagem. O primeiro recorte apresenta uma infinidade de tons de verde, tornando difícil a segregação entre as feições. Em relação à Omissão, a classe "Campo Sujo" foi a que apresentou maior índice, relatando uma certa confusão de classificação dos pixels dessa classe para outras classes.

Tabela 3: Erros de Comissão e Omissão Recorte 1

\begin{tabular}{ccc}
\hline Classes & $\begin{array}{c}\text { Comissão } \\
(\mathbf{\%})\end{array}$ & $\begin{array}{c}\text { Omissão } \\
\mathbf{( \% )}\end{array}$ \\
\hline Vegetação Densa & 40,91 & 26,42 \\
Campo Limpo & 3,41 & 5,03 \\
Campo Sujo & 30,00 & 39,66 \\
Solo Exposto & 0,00 & 0,00 \\
Sombra & 0,00 & 0,00 \\
\hline
\end{tabular}

Em relação á segunda imagem classificada (Figura 5 - Recorte 2), as classes "Solo Exposto", "Campo Limpo", "Campo Sujo" e "Corpos Hídricos" apresentaram, visualmente, resultados satisfatórios. A vegetação de "Mata Ciliar" foi identificada com precisão, permitindo a análise da defasagem de cobertura vegetal segundo legislação ambiental vigente, o Código Florestal nㅜㅜ 12.651 de 2012. Nesse caso, em específico, como o curso d 'água possui metragem maior que 10 metros, a APP deveria ter 50 metros, o que não ocorre na imagem classificada. Nesse tipo de análise em corpos hídricos, o conhecimento sobre a legislação atual e o histórico da área se faz necessário para a decisão sobre os procedimentos de recuperação ambiental na área de preservação.

A Tabela 3 mostra as áreas de cada feição correspondente ao uso e ocupação do solo presente no recorte 2. Nesse mapa temático a feição "Campo Sujo" é predominante, ocupando 12,741744ha da área classificada. A feição com menor relevância é a classe "Agua", com 1,03589 ha. Nessa cena, o índice Kappa foi 0.9583, o que classifica 


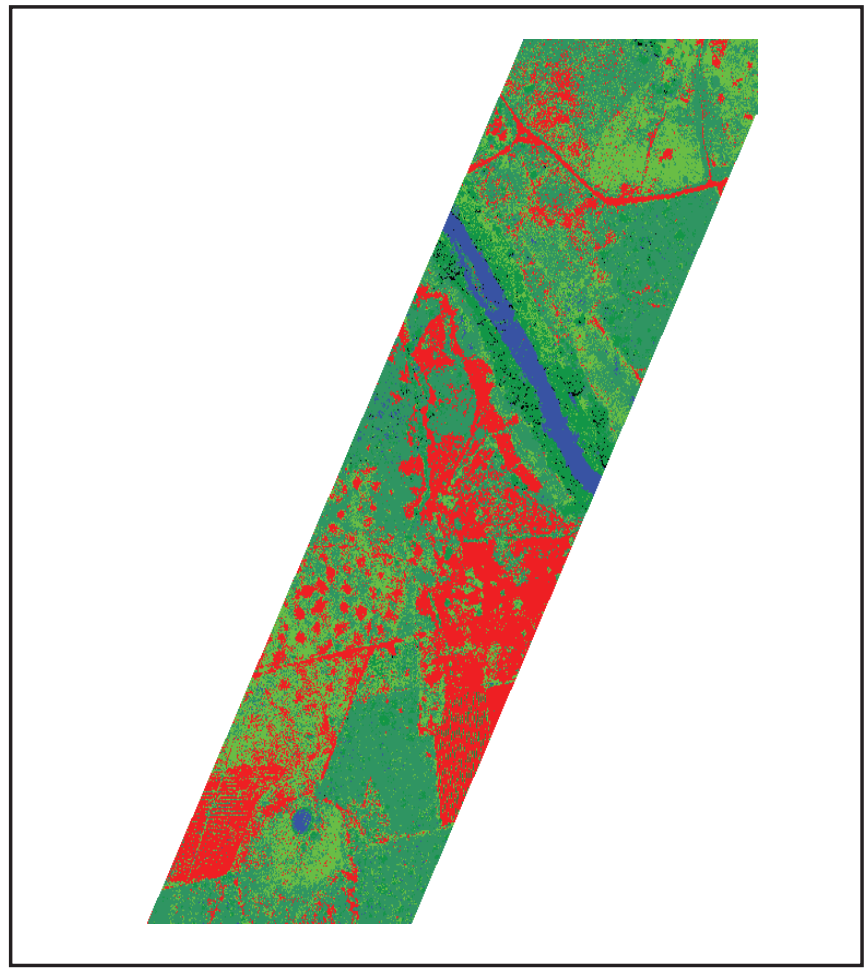

Figura 5 - Imagem classificada referente ao Recorte 2

a segmentação como "Excelente", segundo a referência de concordância (Tabela 1). As feições "Água" e "Campo Sujo" apresentam maiores erros de comissão (Tabela 4), indicando que $71,13 \%$ de suas áreas foram afetadas/somadas, erroneamente, com pixels de outras classes. Por outro lado, cinco classes apresentaram $0 \%$ de Omissão, são elas: "Mata Ciliar", "Campo Limpo", "Campo Sujo" e "Solo Exposto", apontando que nenhum ou poucos pixels de outras classes tenham sido inseridos nessas feições. Todas as classes, com exceção da "Sombra", apresentaram relativamente baixos valores de erros de omissão, o que significa que quase todos os pixels verdadeiramente pertencentes a essas classes foram rotulados corretamente.

Tabela 4: Erros de Comissão e Omissão Recorte 2

\begin{tabular}{ccc}
\hline Classes & $\begin{array}{c}\text { Comissão } \\
(\mathbf{\%})\end{array}$ & $\begin{array}{c}\text { Omissão } \\
\mathbf{( \% )}\end{array}$ \\
\hline Mata Ciliar & 2,37 & 0,00 \\
Campo Limpo & 8,23 & 0,00 \\
Campo Sujo & 14,29 & 0,00 \\
Solo Exposto & 0,00 & 0,00 \\
Sombra & 0,00 & 47,19 \\
Água & 5,35 & 3,04 \\
\hline
\end{tabular}

Na terceira imagem classificada (Figura 6: Recorte 3), nota-se um predomínio das áreas de "Campo Sujo" e "Campo Limpo". Destaca-se que o classificador deu ótima resposta na separação dessas duas classes; isso se deu pela diferença significativa de tonalidade das classes.

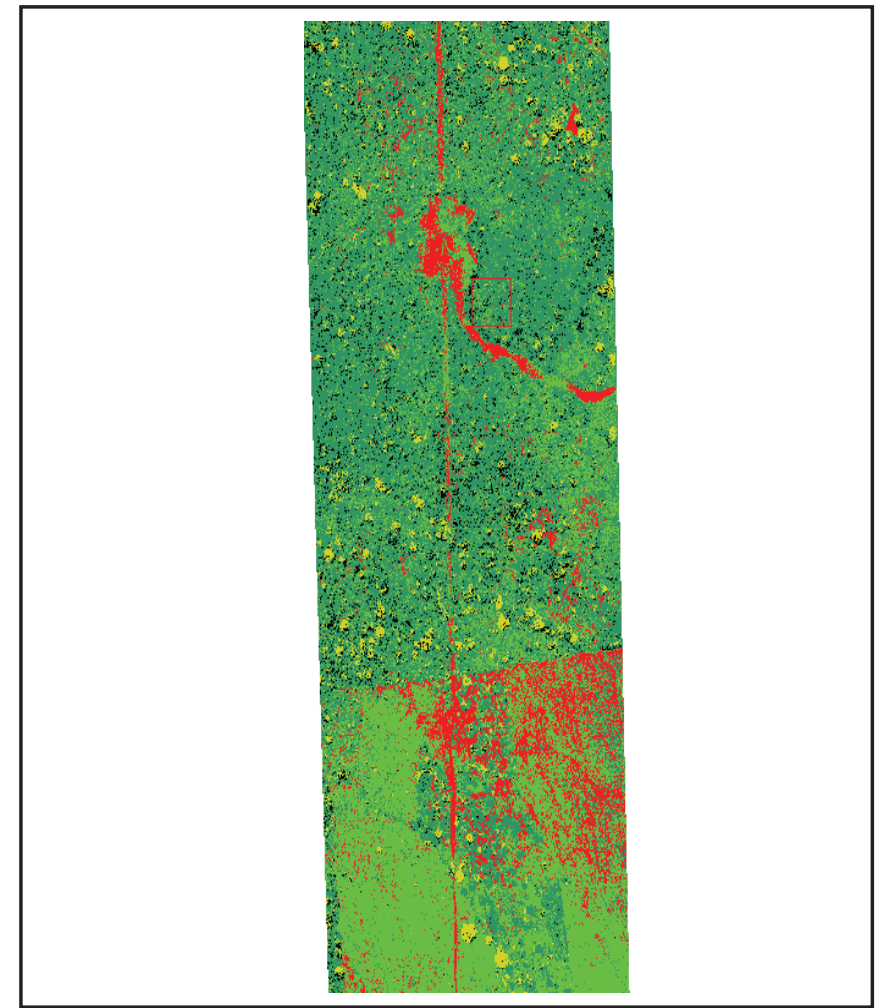

Figura 6 - Imagem classificada referente ao Recorte

Nas regiões Sul e Leste da imagem, os fragmentos de Pastagem, que são enquadrados em "Campo Limpo", foram visualmente bem identificados. Para o Recorte 3, a categoria "Campo Sujo" é predominante, sendo a categoria "Vegetação Densa", a menos expressiva. Os dados de áreas dessas duas feições são 11,753 871 ha e 1,174 789 ha, respectivamente.

Nos locais onde estão locadas as Torres, verificase a predominância de aberturas na vegetação, feitas de maneira intencional para instalação e manutenção dessas estruturas. Percebe-se também a existência de trechos com solo exposto nas proximidades das torres, com ocorrências mais fortes nas classes "Campo Sujo" e "Campo Limpo". São pontos que merecem atenção especial, pois possuem potencial para o desenvolvimento de processos erosivos.

O índice Kappa, medido na classificação do recorte 3, foi de 0,8156 , colocando a classificação também na classe "Excelente", com padrões mínimos de aceitação. As classes "Campo Limpo" e "Campo Sujo" apresentaram maior erro referente à Comissão (Tabela 5), indicando uma confusão na distinção dessas classes com as demais existentes na cena. Em relação à Omissão, somente a classe "Campo Sujo" não apresentou problemas.

Com relação às percepções referentes à classificação da quarta imagem (Figura 7: Recorte 4), a grande variabilidade de tonalidades, alusivas principalmente ao "solo exposto", fizeram com que, nesse trecho da linha de transmissão, fossem realizados vários testes a fim de se obter o melhor resultado. Os testes foram realizados alterando as diferentes classes de "solo exposto" exis- 
Tabela 5: Erros de Comissão e Omissão Recorte 3

\begin{tabular}{ccc}
\hline Classes & $\begin{array}{c}\text { Comissão } \\
\mathbf{( \% )}\end{array}$ & $\begin{array}{c}\text { Omissão } \\
\mathbf{( \% )}\end{array}$ \\
Vegetação Densa & 0,00 & 10,00 \\
Campo Limpo & 37,12 & 18,49 \\
Campo Sujo & 25,37 & 0,00 \\
Solo Exposto & 0,00 & 25,89 \\
Sombra & 0,00 & 15,73 \\
\hline
\end{tabular}

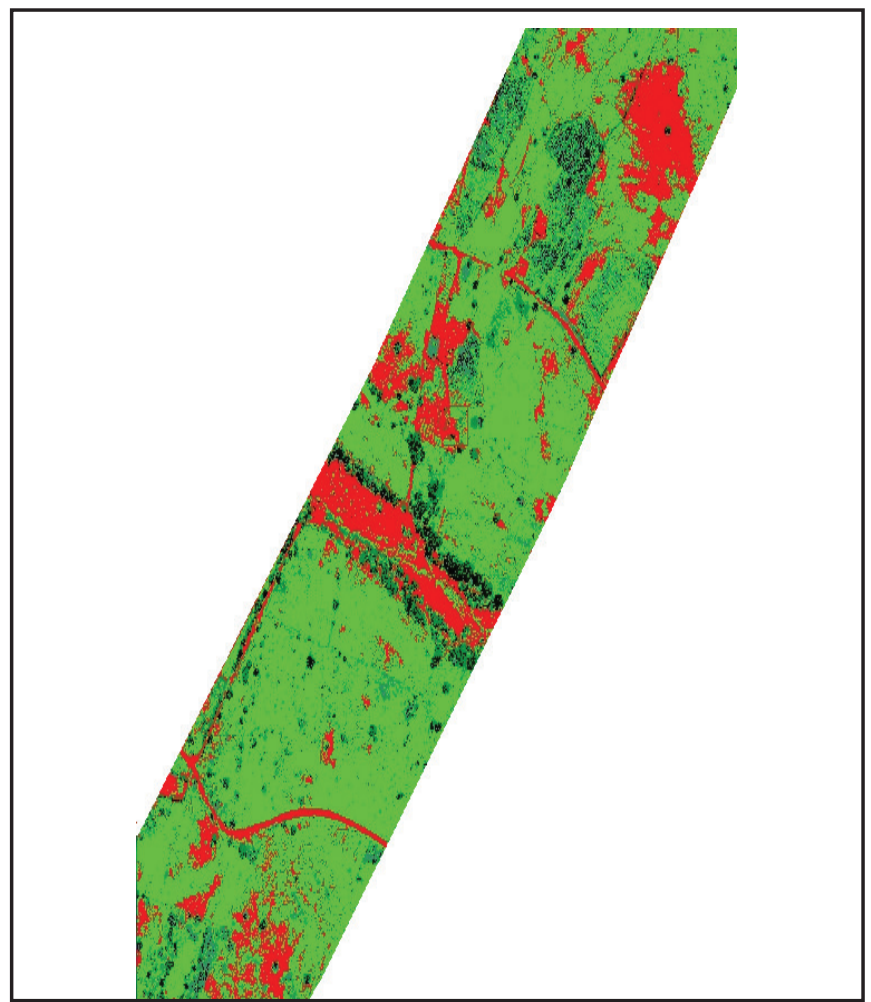

Figura 7 - Imagem classificada referente ao Recorte 4

tentes. A imagem resultante apresenta a predominância de "Campo Limpo" e "Solo Exposto", mostrando o potencial uso antrópico da região. Percebe-se a ausência de vegetação nativa no entorno do curso d'água presente na cena, havendo a necessidade de recomposição vegetal da APP, segundo legislação vigente, de aproximadamente 50 metros para cada margem.

No resultado obtido com o recorte 4, o índice Kappa foi de 0.9935. Com relação à Comissão (Tabela 6), apenas "Campo Limpo" e "Campo Sujo" apresentaram valores não nulos, porém de baixa magnitude, mostrando a eficiência do classificador. Em relação à Omissão, o maior erro encontrado foi o referente à feição "Sombra", com 4,08\%. Pelos baixos índices de Comissão e Omissão, essa imagem apresentou a melhor resposta em relação aos três outros recortes estudados.

A análise global do uso e ocupação do solo é de suma importância para a identificação dos pontos de maior
Tabela 6: Erros de Comissão e Omissão Recorte 4

\begin{tabular}{ccc}
\hline Classes & $\begin{array}{c}\text { Comissão } \\
(\mathbf{\%})\end{array}$ & $\begin{array}{c}\text { Omissão } \\
\mathbf{( \% )}\end{array}$ \\
\hline Mata Ciliar & 0,00 & 0,00 \\
Campo Limpo & 8,70 & 0,00 \\
Campo Sujo & 2,60 & 1,32 \\
Solo Exposto & 0,00 & 0,43 \\
Sombra & 0,00 & 4,08 \\
\hline
\end{tabular}

fragilidade ambiental do empreendimento; de maneira sucinta, os pontos de fragilidade ambiental dizem respeito aos impactos físicos que ocorrem principalmente em relação às modificações ocorridas com a vegetação e com o solo exposto. Em uma análise ambiental geospacial podem ser observados três principais fatores: as características de vegetação, quantidade de solo exposto e o alto índice de uso antrópico com a utilização agrícola ou movimentações relacionadas a manutenção das torres na região.

De acordo com a Tabela 2, a área estudada possui 36,3268ha de "Campo Sujo", sendo a classe dominante nas áreas analisadas, o que mostra um aspecto de conservação ambiental relevante na região. A região estudada possui como segunda e terceira classe dominante o "Campo Limpo" e "Solo Exposto" relatando a importância e representatividade do uso antrópico.

\subsection{Segmentação da imagem isolada e integra- da com dado LiDAR}

No processo de classificação, após a segmentação, foram coletadas as seguintes amostras para as feições de uso e ocupação do solo: Solo Exposto, Campo Sujo, Vegetação de Mata Ciliar, Edificação, Água e Sombreamento. Ressalta-se que foram coletadas dezenas de amostras, com centenas de pixels cada uma, tanto para treinamento quanto para verificação de erros (kappa, comissão e omissão).

Os testes foram realizados apenas no Recorte 2, devido ao fato de se ter imagem/fotos e dados LiDAR da região. O primeiro teste foi realizado com a segmentação e classificação da imagem/foto, utilizando o classificador vizinho mais próximo para rotular os segmentos. $\mathrm{O}$ segundo teste foi realizado com a segmentação e classificação da imagem/foto integrada com dados LiDAR. $\mathrm{Na}$ análise foi definido como recorte 2-a, o recorte sem Laser, e como recorte 2-b, a imagem integrada com dado LiDAR.

Os resultados obtidos com os recortes 2-a e 2-b estão ilustrados nas Figuras 08 e 09, respectivamente. 


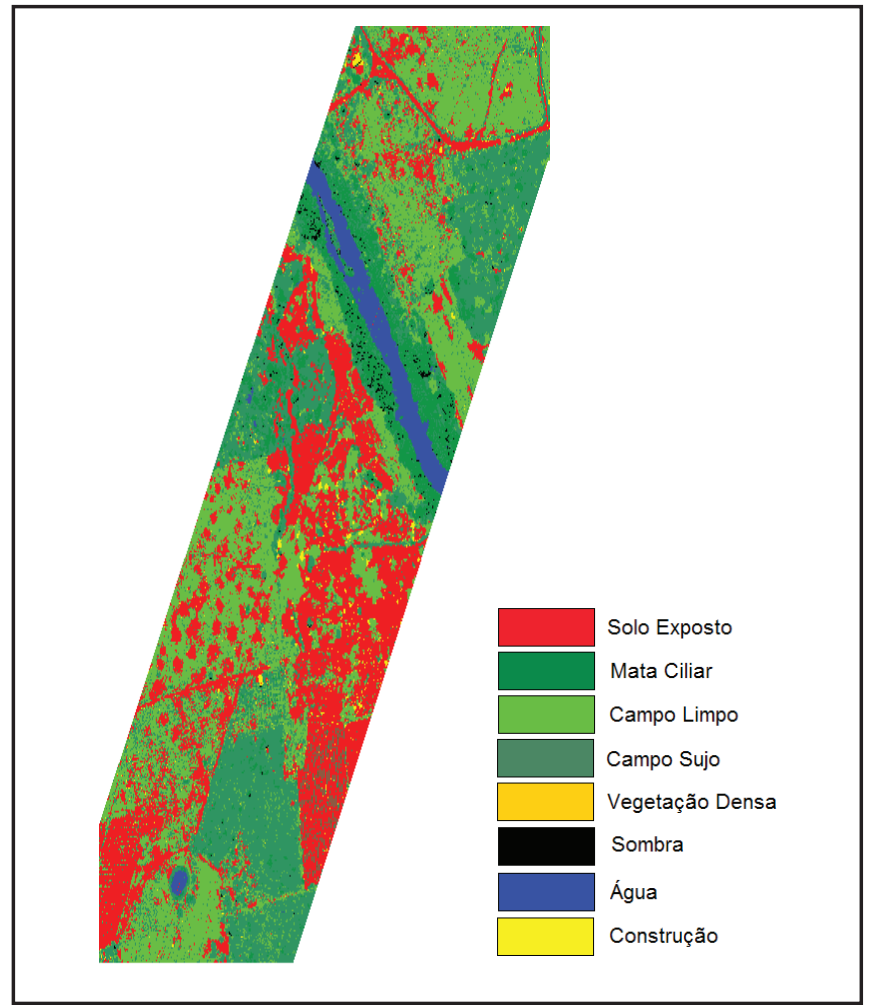

Figura 8 - Imagem classificada referente ao Recorte 2a (sem dados Laser)

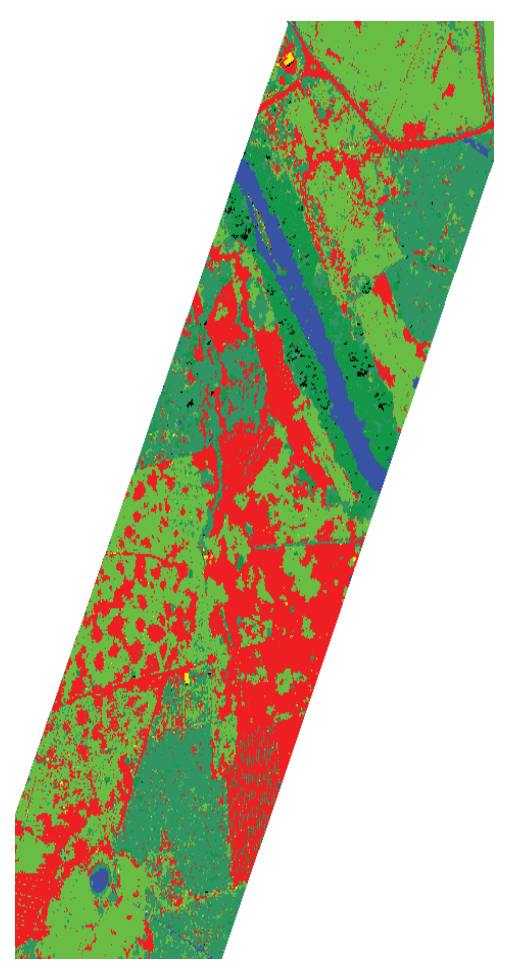

Figura 09: Imagem classificada referente ao Recorte $2 b$ (com dados Laser).

No resultado obtido com o recorte 2-a, o índice Kappa foi 0.9674 , o que classifica a segmentação como "Excelente", segundo a tabela de concordância (Tabela 1). As feicões
"Edificação" e "Mata Ciliar" apresentam maiores erros de comissão (Tabela 7), indicando que aproximadamente $15 \%$ de suas áreas foram afetadas/somadas, erroneamente, com pixels de outras classes. Por outro lado, a classe "solo exposto" apresentou baixo valor de erro de comissão $(0.1 \%)$, apontando que poucos pixels de outras classes tenham sido inseridos nessa feição. Todas as classes apresentaram relativamente baixos valores de erros de omissão, o que significa que quase todos os pixels verdadeiramente pertencentes a essas classes foram rotulados corretamente. A feição "mata ciliar" apresentou maior erro (8.88\%), enquanto a classe "edificação" exibiu o menor, com um erro de apenas $0.74 \%$.

Tabela 7: Erros de Comissão e Omissão medidos na classificação da imagem sem Laser

\begin{tabular}{ccc}
\hline Classes & $\begin{array}{c}\text { Comissão } \\
(\mathbf{\%})\end{array}$ & $\begin{array}{c}\text { Omissão } \\
\mathbf{( \% )}\end{array}$ \\
\hline Água & 0.00 & 0.00 \\
Mata Ciliar & 15.11 & 8.88 \\
Edificação & 15.56 & 0.74 \\
Campo Limpo & 4.01 & 3.45 \\
Campo Sujo & 4.62 & 4.39 \\
Solo Exposto & 0.10 & 2.63 \\
\hline
\end{tabular}

No recorte 2-b, o índice Kappa medido foi 0.9949, classificando a segmentação como "Excelente", segundo a tabela de concordância (Tabela 1). Em comparação com o resultado obtido com o recorte 2 , houve um melhor resultado na classificação, mostrando, portanto, um ganho na utilização de dados LiDAR integrados com fotografias áreas.

A Tabela 8 mostra que os valores de erros de comissão e omissão também são inferiores aos erros apresentados na classificação com a imagem isolada (Tabela 7), com exceção da feição "solo exposto", que apresenta erro de comissão levemente superior $(0.02 \%)$ com a integração imagem/LiDAR. Isso pode ser explicado pelo fato de a feição "solo exposto" não apresentar grandes destaques nos dados LiDAR, isto é, não sofre alterações altimétricas bruscas, como é o caso de construções e árvores. Outra feição que merece destaque é a "mata ciliar", que apresenta erro de omissão similar em

Tabela 8 - Erros de Comissão e Omissão medidos na classificação da imagem integrada com LiDAR

\begin{tabular}{ccc}
\hline Classes & $\begin{array}{c}\text { Comissão } \\
\mathbf{( \% )}\end{array}$ & $\begin{array}{c}\text { Omissão } \\
\mathbf{( \% )}\end{array}$ \\
Água & 0.00 & 0.00 \\
Mata Ciliar & 0.00 & 8.77 \\
Edificação & 4.62 & 0.43 \\
Campo Limpo & 0.18 & 0.14 \\
Campo Sujo & 0.00 & 0.00 \\
Solo Exposto & 0.12 & 0.58 \\
\hline
\end{tabular}


ambos os testes. Esse caso é facilmente explicado devido a existência de árvores de grande porte, com características de "mata ciliar", mas presentes em regiões afastadas dos corpos d'água.

Com base nos resultados apresentados nesse estudo, o fluxograma metodológico proposto mostrou ser eficiente $\mathrm{n}$ a identificação dos impactos causados pelo setor de produção de energia elétrica no Brasil, em específico nos biomas Cerrado e Caatinga. É mostrado ainda que o uso de geotecnologiaspode simplificar os processos de obtenção de diagnósticos ambientais, se comparado com as técnicas tradicionais de levantamentos, que demandam muito tempo e são mais onerosos.

A utilização de imagens e dados LiDAR, com alta resolução espacial, aliada às técnicas consagradas como a classificação MaxVer e segmentação de imagens, podem apresentar resultados satisfatórios no que diz respeito à identificação de alvos de interesse, que apontam os processos ambientais, para tomada de decisão, comprovado nesse estudo para o caso de projeto de LT.

\section{Conclusão}

Com base nos resultados, nota-se que os avanços científico-tecnológicos, como o avanço no processo de obtenção e na qualidade das imagens digitais, o aperfeiçoamento de softwares de processamento digital de imagens, somados ao aprimoramento dos sistemas de gestão e de legislação ambiental, são fundamentais para minimizar e controlar os impactos ambientais causados pela pressão antrópica ao ambiente.

A classificação supervisionada com a utilização de fotografias áreas e a metodologia da Máxima-verossimilhança apresentam ótimos resultados quanto ao uso e ocupação do solo e os respectivos impactos ambientais identificados, sendo que os erros identificados em sua maioria são passíveis de ajustes e correções manuais. Salienta-se que as Torrese linhas/cabos de alta tensão já encontram-se instalados na área de estudo, sendo completamente impossível detectar a relação direta de impacto ambiental referente á sua instalação. Dois pontos de fragilidade foram identificados, principalmente os processos de ravinamento e a interação com a Vegetação Nativa.

Com relação ao processo de segmentação, se comparado a segmentação com a imagem pura e a imagem integrada com dados laser scanner, a segunda experiência apresentou melhores resultados segundo índice Kappa, e os erros de Comissão e Emissão. O que projeta perspectivas de refinamento dos resultados a serem apresentados comparando os métodos de classificação supervisionada e segmentação em trabalhos futuros. Em relação ao solo, os impactos, principalmente no entorno das instalações, ocorrem em virtude do transito de veículos/maquinário, desmates ou podas. O solo uma vez desnudo pode desencadear processos de ravinamento e por consequência voçorocas; que além de trazer desequilíbrio ao ambiente, pode acarretar danos a estrutura física das redes.

A interação linha de transmissão e vegetação arbórea é temática complexa, por exemplo a importância ecológica dos fragmentos florestais existentes em uma área que podem representar nichos específicos de espécies de animais ameaçados ou plantas. Outros fatores são a negativa, ou não, de supressão de vegetação nativa pelo órgão ambiental licenciador e a importância econômica de uma área plantada (em caso de cultivos).

Outros impactos ambientais, referentes ao uso e ocupação dos solos,são identificados. Os próprios proprietários de terra que ocupam as faixas de servidão com uso controlado, em uma primeira percepção, utilizam do espaço para a agricultura e desmatam regiões de vegetação nativa. Essas áreas merecem atenção especial por parte da operadora das linhas de transmissão, para que a responsabilidade dos danos causados ao meio ambiente não seja compartilhada .

\section{Agradecimentos}

Os autores agradecem à Companhia Hidroelétrica do Alto do São Francisco - CHESF pela disponibilização dos dados espaciais utilizados na pesquisa.

\section{Referências}

ANDRADE A. F., CENTENO, J. A. S. (2003). Integração de informações espectrais e de forma na classificação de imagens com redes neurais. Boletim de Ciências Geodésicas, v. 09 (02), 217-231.

ANEEL - (2014) Agência Nacional de Energia Elétrica Linhas de Transmissão. Disponível em: <http://www. aneel.gov.br/area.cfm?id Area=67> . Acesso em: 28/04/2014.

ARCOVERDE, G. F. B., EPIPHANIO, J. C. N., MARTINS, V. A., MAEDA, E. E., FONSECA, L. M. G. (2010). Mapeamento de citrus: avaliação de classificações por árvore de decisão. Revista Brasileira de Cartografia, v. 62 (1), 91-102.

B AATZ, M., SCH ÄPE, A. (2000). Multiresolution segmentation: an optimization approach for high quality multi-scale image segmentation. Journal of Photogrammetry and Remote Sensing, v.58, 12-23.

BLASCHKE, T. (2010). Object-based image analysis for remote sensing. Journal of Photogrammetry and Remote Sensing, v.65, 02-16.

BOtELHO, M. F., CENTENO, J. A. S. (2005). Uso integrado de imagem de alta resolução espacial e altura derivada do LASER Scanner na escolha do classificador orientado a região. Boletim de Ciências Geodésicas, 
Curitiba, v. 11 (01), 71-87.

COSTA, D. T., VAZ, J. S., LOPES, J. S. F. (2012). Grandes Impactos Ambientais no Mundo. Caderno de Meio Ambiente e Sustentabilidade. V. 01(01), 56-73.

HAY, G. J., CASTILLA, G., (2008). Geographic ObjectBased Image Analysis (GEOBIA): A new name for a new discipline. In: Blaschke, T., Lang, S., Hay, G(Eds.), Object Based Image Analysis. Springer, New York, 93-112.

LANDIS, J. R., KOCH, G. G. (1977). The measurement of observer agreement for categorical data. Biometrics, v. 33(01), 159-174.

MAKARAU, A., PALUBINSKAS, G., REINARTZ, P. (2011). Multi-sensor data fusion for urban area classification. In: Urban Remote Sensing Event 2011, Munique, 21-24.

PINHO, C. M. D. DE, FONSECA, L. M. G., KORTING, T. S., ALMEIDA, C. M. DE, KUX, H. J. H. (2012). Land-cover classification of an intraurban environment using high-resolution images and object-based image analysis. International Journal of Remote Sensing, v.33, 5973-5995.

PLATT, R. V., RAPOZA, L. (2008). An evaluation of an object-oriented paradigm for land use/land cover classification. The Professional Geographer, v.60, 87-100.

RIMA - (2014). Relatório de Impacto Ambiental LT $230 \mathrm{Kv}$ Ibicoara/ Brumado II C1 e SE Ibicoara 230/138. Disponível em: <www. chesf.gov.br $>$. Acessado em: 08/10/2014.

SILVA, C. R., PACHECO, A. P., VALENTE, S. (2014). Análise de dados SRTM e imagens CBERS 2b na identificação de áreas susceptíveis à ocupação irregular em faixa de servidão de linha de transmissão de energia elétrica. Ciência e Natura, v. 36(02), 128-136. 